\title{
30 EFFICACY OF DIFFERENT DOSES OF RITUXIMAB FOR THE TREATMENT OF RA: DATA FROM THE CERERRA
} COLLABORATION

Katerina Chatzidionysiou, ${ }^{1}$ Elisabeth Lie, ${ }^{2}$ Evgeny L Nasonov, ${ }^{3}$ Galina Lukina, ${ }^{3}$ Merete L Hetland, ${ }^{4}$ Ulrik Tarp, ${ }^{5}$ loan Ancuta, ${ }^{6}$ Karel Pavelka, Dan C Nordström, ${ }^{8}$ Cem Gabay, ${ }^{9}$ Helena Canhao, ${ }^{10}$ Matija Tomsic, ${ }^{11}$ Piet L C van Riel, ${ }^{12}$ Juan J Gomez-Reino, ${ }^{13}$ Tore K Kvien, ${ }^{2}$ Ronald F van Vollenhoven ${ }^{1}{ }^{1}$ Karolinska Institute, Stockholm, Sweden; ${ }^{2}$ Diakonhjemmet Hospital, Oslo, Norway; ${ }^{3}$ ARBITER, Institute of Rheumatology, Moscow, Russia; ${ }^{4}$ Copenhagen University Hospital at Glostrup, on behalf of DANBIO, Copenhagen, Denmark; ${ }^{5}$ Aarhus University Hospital, Aarhus, Denmark; ${ }^{6}$ Cantacuzino Hospital, Bucharest, Romania; ${ }^{7}$ Institute of Rheumatology, Department of Experimental Rheumatology, 1st Faculty of Medicine, Charles University in Prague, Prague, Czech Republic; ${ }^{8}$ ROB-FIN, Helsinki University Central Hospital, Helsinki, Finland; ${ }^{9}$ SCOM registry, University Hospitals of Geneva, Geneva, Switzerland; ${ }^{10}$ Lisbon Medical Academic Medical Center on behalf of Rheumatic Diseases Portuguese Register Lisbon, Portugal; ${ }^{11}$ University Medical Centre Ljubjana, Ljubljana, Slovenia; ${ }^{12}$ Radboud University Nijmegen Medical Centre, Nijmegen, Netherlands; ${ }^{13}$ Hospital Clinico Universitario, Santiago, Spain 
Background/objectives The approved dose of RTX in RA is $1000 \mathrm{mg} \mathrm{x} 2$, but some data have suggested similar clinical efficacy with $500 \mathrm{mg} \times 2$. The purpose of this analysis was to compare the efficacy of the two dosages given as first or second treatment course.

Methods Ten European registries submitted anonymised datasets with demographic, efficacy and treatment data for patients who had started RTX. Efficacy of treatment and retreatment was assessed based on DAS28 reductions and EULAR responses after 6 months.

Results Data on RTX dose were available for 2873 out of 3266 patients in CERERRA. 2625 (91.4\%) and 248 (8.6\%) patients received $1000 \mathrm{mg} x 2$ and $500 \mathrm{mg} x 2$, respectively. Patients who were treated with the lower dose (LD) were significantly older (mean \pm SD: $55.2 \pm 15.8$ vs 52.6 \pm 12.6 , years, $p=0.002$ ), had longer disease duration (13.6 611.9 vs $10.9 \pm 8.2$, years, $p<0.0001$ ), higher number of prior DMARDs $(2.6 \pm 1.3$ vs $2.4 \pm 1.4, p=0.04)$ but lower number of prior biologics $(0.7 \pm 0.9$ vs $1.0 \pm 1.0, p<0.0001)$ and lower baseline DAS28 ( $5.7 \pm 1.3$ vs $5.9 \pm 1.3, \mathrm{p}=0.02)$ than those treated with the higher dose (HD). Additionally they were less likely to receive concomitant DMARDs $(72.6 \%$ vs $83.1 \%, p<0.0001)$ but more likely to receive concomitant corticosteroids $(65.7 \%$ vs $59.3 \%$, p=0.03).

Both dosages lead to significant clinical outcomes at 6 months. Patients with the HD achieved numerically slightly greater DAS28 reductions at 6 months compared to those treated with the LD (mean DeltaDAS28 \pm SD $=1.9 \pm 1.4$ vs $1.7 \pm 1.4, p=0.5$ corrected for baseline DAS28). Similar percentages of patients achieved EULAR good response (55.2\% vs $50 \%, \mathrm{p}=\mathrm{NS})$ and remission $(10.5 \%$ vs $10.7 \%, \mathrm{p}=\mathrm{NS})$ in the $\mathrm{HD}$ and $\mathrm{LD}$ groups, respectively.

At $6 \pm 1.5$ months 579 patients received retreatment with $\mathrm{HD}$ RTX and 26 patients with LD. Patients who received a different dose at retreatment than at first treatment, as well as patients who were retreated at different time points during the first year, were disregarded from the analysis. Retreatment with HD led to even greater DAS28 reductions at 12 than at 6 months (DeltaDAS28 $6 \mathrm{~m}=1.85 \pm 1.19$, DeltaDAS28 $12 \mathrm{~m}=2.52 \pm 1.47$, p by paired $t$ test $<0.0001)$, while retreatment with LD led to 